\title{
Control of the rheological structure of the lithosphere on the inward migration of tectonic activity during continental rifting
}

\author{
Giacomo Corti $^{\mathrm{a}, *}$, Giorgio Ranalli ${ }^{\mathrm{b}}$, Genene Mulugeta ${ }^{\mathrm{c}}$, Andrea Agostini ${ }^{\mathrm{d}}$, Federico Sani ${ }^{\mathrm{d}}$, Alessandro Zugu ${ }^{\mathrm{d}}$ \\ a CNR, Consiglio Nazionale delle Ricerche, Istituto di Geoscienze e Georisorse, U.O. Firenze, Via G. La Pira, 4, 50121 Florence, Italy \\ ${ }^{\mathrm{b}}$ Department of Earth Sciences and Ottawa-Carleton Geoscience Centre, Carleton University, Ottawa, Canada K1S 5B6 \\ c The Baltic University Programme, Centre for Sustainable Development, Uppsala University, Villavagen 16, 75236 Uppsala, Sweden \\ d Dipartimento di Scienze della Terra, Università degli Studi di Firenze, Via G. La Pira, 4, 50121 Florence, Italy
}

\section{A R T I C L E I N F O}

\section{Article history:}

Received 8 February 2010

Received in revised form 3 May 2010

Accepted 11 May 2010

Available online 24 May 2010

\section{Keywords:}

Continental rifting

Rift evolution

Lithosphere rheology

\begin{abstract}
A B S T R A C T
Analogue models are used to analyse the parameters controlling the evolution of extensional deformation in continental rifts. Models are deformed in a centrifuge and simulate the continental lithosphere floating and extending above a low-viscosity asthenosphere. Model results reproduce the typical evolution of deformation during continental narrow rifting, with early activation of large boundary faults and basin subsidence, followed by their abandonment and localization of tectonic activity in internal faults near the centre of the rift. The experiments document the strong influence exerted by the thickness of both brittle and ductile crustal layers and syn-rift sediment accumulation on the evolution of deformation, namely on the amount of bulk extension preceding inward fault migration. Thin upper and/or lower crust and absent or low syn-rift sedimentation promote a rapid abandonment of boundary faults and a transition to in-rift fault development for low amounts of extension; conversely, thick upper and/or lower crust and high syn-rift sediment accumulation favour prolonged slip on boundary faults and delayed development of internal faulting. The experimental results suggest that the inward migration of faulting during extension of continental lithosphere results from the interplay between the ductile stresses acting at the base of the upper crust and the total resistance of this brittle layer.
\end{abstract}

(C) 2010 Elsevier B.V. All rights reserved.

\section{Introduction}

Studies of active continental rifts such as the Main Ethiopian Rift in East Africa document a progressive narrowing of the volcano-tectonic activity towards the break-up stage, with a typical evolutionary sequence characterised by early activation of large boundary faults and rift valley subsidence followed by focusing of faulting and magmatism in the axial rift valley (e.g., Ebinger, 2005). The abandonment of the large boundary faults and the inward migration of faulting, associated with the development of fault swarms accommodating almost the whole plate separation and focusing strong magma upwelling and emplacement in the lithosphere, are believed to be characteristic of the continental break-up immediately preceding oceanization (e.g., Ebinger, 2005; Corti, 2009).

Comparison of continental rifts and passive margins worldwide (e.g., Ziegler and Cloetingh, 2004) suggests that the timing (and the amount of bulk extension) of this inward migration of deformation and-consequently-the duration of the rifting process is highly variable, reflecting the complexity of the thermo-mechanical process

\footnotetext{
* Corresponding author. Tel.: + 390552757528.

E-mail address: giacomo.corti@unifi.it (G. Corti).
}

by which continents break. This is turn may be dictated by the complex structure and history of continental plates, where extension affects a pre-deformed, highly anisotropic lithosphere in which lateral variations in thickness and strength may strongly affect the process (e.g., Cloetingh et al., 1995).

Recent lithospheric-scale analogue models of continental rifting have focused on different aspects of the rifting process, such as: the different modes of deformation resulting from the extension process (i.e., wide and narrow rifts, core complexes; e.g., Brun, 1999; Michon and Merle, 2003; Corti et al., 2003; Corti, 2005), the dependence of the pattern and evolution of deformation on rift kinematics (e.g., Mart and Dauteuil, 2000; Corti, 2008; Agostini et al., 2009), the role of preexisting lithospheric structure on rift architecture (e.g., Corti and Manetti, 2006; Bonini et al., 2007; Sokoutis et al., 2007; Corti et al., 2007a), the influence of magma injection on extensional deformation (e.g., Corti et al., 2003, 2004, 2007b), or the boundary conditions of displacement (i.e., episodic or steady rifting; Mulugeta and Ghebreab, 2001). Although in some previous studies (e.g., Brun and Beslier, 1996; Brun, 1999; McClay et al., 2002) a progressive narrowing of the tectonic activity was observed during extension, this process and its controlling parameters were not analysed in detail. In this study we expand these previous lithospheric-scale analogue modelling analyses by focusing on the parameters controlling the process of fault migration during narrow 
continental rifting. Our models reproduce the two-phase evolution documented in active continental rifts with the early activation of large boundary faults followed by their (partial) abandonment and development of axial faults. Model results indicate that the pre-rift rheological layering of the continental lithosphere (in particular, the thickness of brittle and ductile layers) and the amount of syn-rift sediment accumulation may strongly affect the amount of bulk extension needed for the inward fault migration and thus the evolution of the rifting process.

\section{Modelling approach}

The experimental set-up was based on a modelling approach in which experiments reproducing continental rifting are performed in an artificial gravity field of $\sim 18 \mathrm{~g}$ by using the large capacity centrifuge at the Tectonic Modelling Laboratory of the Institute of Geosciences and Earth Resources (National Research Council of Italy) at the EarthSciences Department of the University of Florence. Following the setup adopted in Corti (2008) and Agostini et al. (2009), the experiments simulated the extending continental lithosphere (crust + thin lithospheric mantle) floating above a low-viscosity material representing the asthenosphere (Fig. 1). The models were built inside a transparent rectangular Plexiglas box and confined by two moveable side walls; removal of rectangular blocks (spacers) at the sides of these moving walls allowed vertical thinning and lateral extension of the models in response to the centrifugal forces to fill the empty space (Fig. 1a). Sequential removal of spacers during successive runs in the centrifuge was instrumental in controlling the amount and rate of extension (e.g., Corti et al., 2003). The model lithosphere contained a central weak zone (Fig. 1b) that localized deformation during progressive extension (e.g., van Wijk, 2005; Corti, 2008). This is a realistic approximation for the natural process of continental rifting at a regional scale, where extensional stresses are applied to a pre-deformed, anisotropic lithosphere and deformation tends to follow the trend of pre-existing weaknesses (e.g., Dunbar and Sawyer, 1989; Versfelt and Rosendahl, 1989; Morley, 1999; Tommasi and Vauchez, 2001; Ziegler and Cloetingh, 2004; Keranen et al., 2009).

\subsection{Rheological layering and experimental materials}

The models reproduced a brittle-ductile rheological multilayer characteristic of the extending continental lithosphere. The brittle upper crust was simulated with a K-feldspar powder, showing a linear strength increase with depth typical of frictional materials (Fig. 1c). Conversely, the ductile lower portion of the crust was simulated by three different levels made of a plasticine-Polydimethylsiloxane mixture, with constant density but decreasing viscosity (strength) with depth (see detailed description in Agostini et al., 2009), thus allowing approximating the temperature-related decrease in strength with depth in natural ductile layers (Fig. 1c). The lithospheric upper mantle was simulated by two different layers (made of a plasticinePDMS mixture and silicone-corundum sand-oleic acid), again showing a constant density but decreasing strength with depth (Fig. 1c). Following previous modelling (e.g., Van Wijk, 2005; Corti and Manetti, 2006; Corti, 2008; Agostini et al., 2009), the weak zone in the centre of the models was made of a silicone-corundum sand-oleic acid mixture and simulated a local increase in crustal thickness which is expected to greatly reduce the integrated resistance of the lithosphere by 1 ) replacing the strong lithospheric mantle material with weak crustal material and 2) increasing initial Moho temperatures and thus softening the crustal materials with respect to the surroundings (e.g., Afonso and Ranalli, 2004). These crustal-mantle layers rested on a low-viscosity silicone-corundum sand-oleic acid mixture simulating the asthenosphere and providing the isostatic support for the deforming model lithosphere (Fig. 1).

Syn-tectonic accumulation of sediments during progressive subsidence of the rift zone was simulated in the experiments. This was

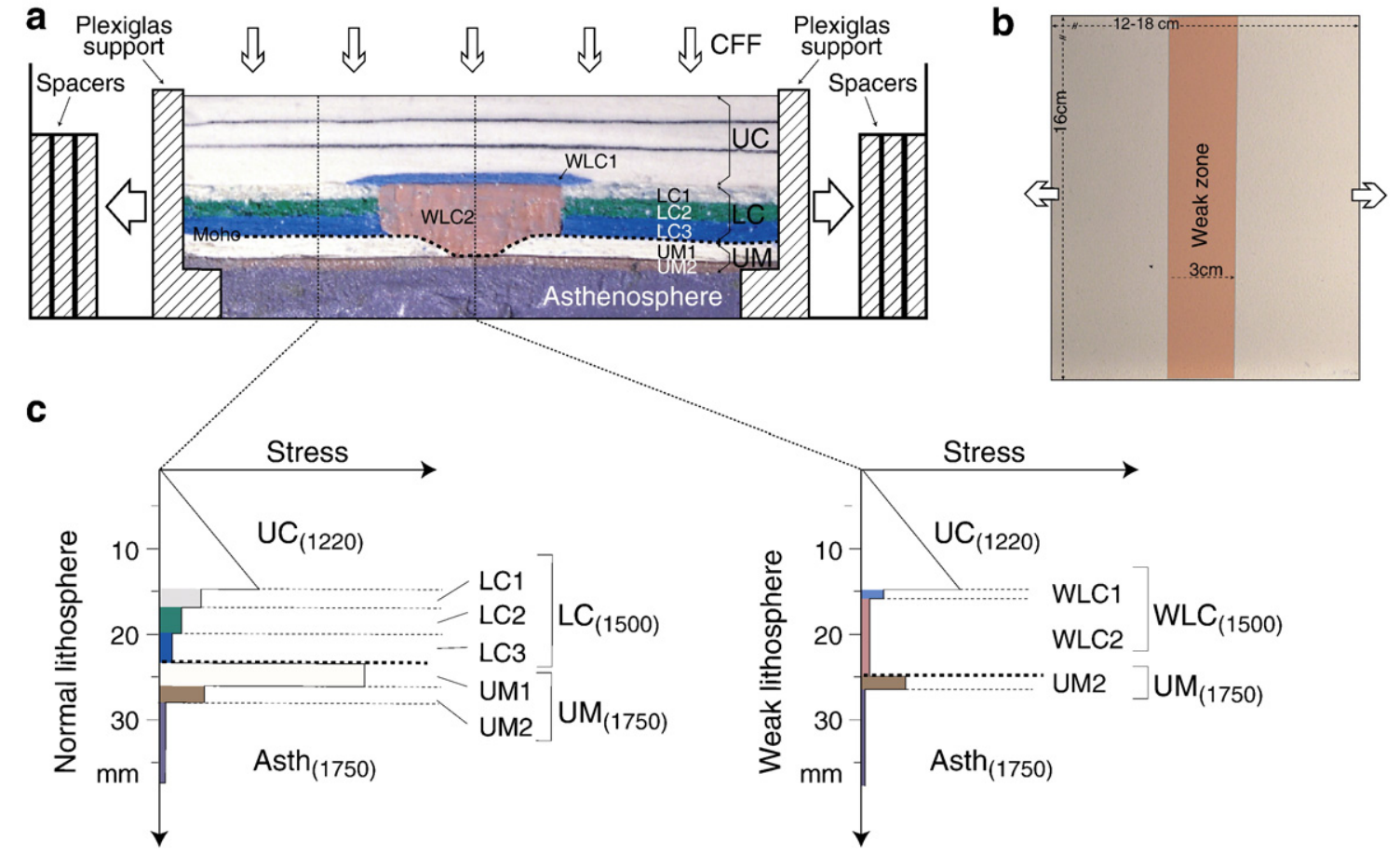

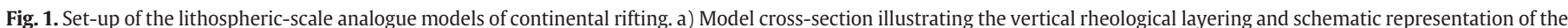

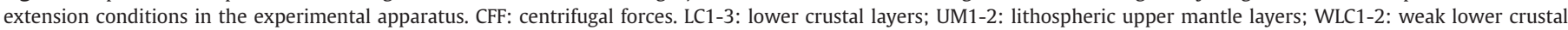

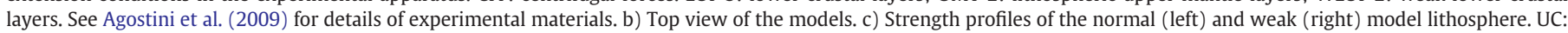
upper crust; Asth: asthenosphere; other symbols as above. Numbers in denote the density of the different materials $\left(\mathrm{kg} \mathrm{m}^{-3}\right)$. 
achieved by filling the rift depression (up to the top of the rift shoulders) with sieved K-feldspar powder each $6 \mathrm{~mm}$ of extension.

\subsection{Scaling}

The geometric scale ratio adopted in the experiment was of $6.7 \times 10^{-7}$ such that $1 \mathrm{~cm}$ in the experiments corresponded to $15 \mathrm{~km}$ in nature, modelling $\sim 42 \mathrm{~km}$ of total extension of a $\sim 50 \mathrm{~km}$-thick continental lithosphere. Dynamic-kinematic similarity (Ramberg, 1981) of gravitational, viscous and frictional stresses acting in the system (e.g., Corti et al., 2004) ensured that the velocity of extension in the models $\left(\sim 10^{-4} \mathrm{~m} \mathrm{~s}^{-1}\right)$ scaled to natural values of 4-6 $\mathrm{mm} \mathrm{a}^{-1}$, a reasonable value for continental rift systems (e.g., Corti, 2008). The total resistance of the lithosphere, scaled from models to nature, was estimated to vary between $\sim 5 \times 10^{12} \mathrm{~N} \mathrm{~m}^{-1}$ (within the central weak area) and $\sim 4 \times 10^{13} \mathrm{~N} \mathrm{~m}^{-1}$ (in the strong surrounding regions), well in the range of estimates for weak/strong natural lithospheres (see Agostini et al., 2009 for details of calculations).

\subsection{Experimental series}

Three series of experiments were performed to analyse the influence of the thickness of brittle and ductile layers and the synrift sediment accumulation on the process of fault migration (Table 1). In each experimental series, the boundary conditions (e.g., velocity of deformation, amount of bulk extension, etc.) were kept constant, apart from the parameter under investigation. In Series 1 and 2 the thickness of the brittle upper crust and ductile lower crust were systematically varied with respect to the standard experiment (Table 1); Series 3 investigated the influence of the syn-rift sedimentation by comparing a model with no sediment accumulation and a model with increased total sedimentation with regard to the standard model (Table 1). Increased sedimentation was achieved by filling the model with K-feldspar powder up to $1 \mathrm{~mm}$ above the top of the boundary faults, thus burying the rift floor and shoulders.

In total 9 experiments are discussed in this paper; each experiment was repeated at least three times and, although the models may have differed in small details, the first order deformation evolution and pattern were always comparable. One of these experiments (standard experiment, see Table 1) was already presented in Agostini et al. (2009), while the other 8 experiments are presented in this paper for the first time.

\section{Experimental results}

In all the experiments, the early stages of deformation were characterized by nucleation of major boundary fault systems at the strong-weak lithosphere boundaries, bordering a subsiding rift depression (Boundary Faults Stage of Corti, 2008 and Agostini et al., 2009; Fig. 2; cf. film in Supplementary Material). The development of minor normal faults, antithetic to the major systems, gave rise to a pair of marginal grabens, delimiting a central horst, as typically observed in previous modelling works (e.g., Mulugeta and Ghebreab, 2001; McClay et al., 2002). In these initial stages, all the extensional deformation was accommodated by slip on boundary and antithetic faults, whereas the floor of the rift depression (central horst) was not affected by detectable deformation (Fig. 2). Increasing extension led to a change in deformation style, with deformation starting to affect the rift floor with development of normal faults forming a graben structure within the central horst (Internal Faults Stage of Corti, 2008 and Agostini et al., 2009; Figs. 2 and 3). During progressive extension, this graben deepened and internal faults accommodated an increasing amount of deformation in parallel with a progressive decrease of the amount of slip along boundary faults (Figs. 2 and 3). Internal faults accommodated more than $\sim 70 \%$ of the total extensional deformation at the end of the experiment (see Agostini et al., 2009). The final structural pattern of the model displayed boundary escarpments and remnants of marginal grabens flanking a rift depression characterized by a graben-in-graben structure caused by activity of internal faults (Figs. 2 and 3).

The different experimental series documented a control of both the ductile and brittle layer thickness on the amount of bulk extension needed for the development of internal faults and thus for the change in deformation style (Figs. 4, 5; Table 1). Whereas in the standard model (brittle thickness $15 \mathrm{~mm}$, ductile thickness $13 \mathrm{~mm}$ ), development of internal faults occurred for $\sim 18 \mathrm{~mm}$ of extension, a reduction of the ductile thickness to $10 \mathrm{~mm}$ and $7 \mathrm{~mm}$ resulted in the earlier development of the central graben at $\sim 15 \mathrm{~mm}$ and $\sim 9 \mathrm{~mm}$ of bulk extension, respectively. Conversely, an increase in the ductile thickness (to $19 \mathrm{~mm}$ ) resulted in a later development of internal faults (at $\sim 24 \mathrm{~mm}$ of bulk extension). Similarly, a reduction in the brittle thickness to $10 \mathrm{~mm}$ and $5 \mathrm{~mm}$ led to an earlier development of internal faults ( $\sim 12 \mathrm{~mm}$ and $\sim 9 \mathrm{~mm}$ of bulk extension, respectively), whereas an increase in the upper crust thickness to $20 \mathrm{~mm}$ resulted in the later migration of faulting (at $\sim 24 \mathrm{~mm}$ of bulk extension).

Although less evident, a similar control on fault migration was observed for the syn-rift sedimentation (see Table 1$)$. When sediment accumulation was absent faults migrated inwards earlier $(\sim 12 \mathrm{~mm}$ of bulk extension) than in the reference model (in which the total sediment accumulation was of $\sim 7 \mathrm{~mm}$ ); however no difference was observed in the case of increased sediment accumulation (total sediment accumulation of $\sim 10 \mathrm{~mm}$ ), either because model evolution was monitored after successive centrifuge runs of $3 \mathrm{~mm}$ of bulk extension making it impossible to resolve variations in the amount of bulk extension lower than this interval, or because the increment in sediment accumulation was too low to induce variations in fault evolution and migration.

Table 1

Characteristics of the different experimental series.

\begin{tabular}{|c|c|c|c|c|c|c|c|}
\hline Experimental series & Model & $\begin{array}{l}\text { Thickness Upper Crust } \\
(\mathrm{mm})\end{array}$ & $\begin{array}{l}\text { Thickness Lower Crust } \\
(\mathrm{mm})\end{array}$ & $\begin{array}{l}\text { Thickness Lith Mantle } \\
(\mathrm{mm})\end{array}$ & $\begin{array}{l}\text { Ductile Thickness } \\
(\mathrm{mm})\end{array}$ & $\begin{array}{l}\text { Total sedimentation } \\
(\mathrm{mm})\end{array}$ & $\begin{array}{l}\text { Fault migration } \\
\text { (mm bulk extension) }\end{array}$ \\
\hline Standard & \#1 & 15 & 8 & 5 & 13 & 7 & 18 \\
\hline \multirow[t]{3}{*}{ Variable LC (Series 1) } & \#2 & 15 & 2 & 5 & 7 & 7 & 9 \\
\hline & \#3 & 15 & 5 & 5 & 10 & 7 & 15 \\
\hline & $\# 4$ & 15 & 14 & 5 & 19 & 7 & 24 \\
\hline \multirow[t]{3}{*}{ Variable UC (Series 2) } & \#5 & 5 & 8 & 5 & 13 & 7 & 9 \\
\hline & \#6 & 10 & 8 & 5 & 13 & 7 & 12 \\
\hline & \#7 & 20 & 8 & 5 & 13 & 7 & 24 \\
\hline \multirow[t]{2}{*}{ Variable sedim (Series 3) } & $\# 8$ & 15 & 8 & 5 & 13 & 0 & 12 \\
\hline & \#9 & 15 & 8 & 5 & 13 & 10 & 18 \\
\hline Test Exp* & \#10 & 15 & 8 & 5 & 13 & 7 & 18 \\
\hline
\end{tabular}

LC: lower crust; Lith: lithospheric; sedim: sedimentation; UC: upper crust.

The velocity of deformation $\left(\sim 510^{-5} \mathrm{~ms}^{-1}\right)$ is constant in all the different experiments.

*Performed with internal vertical markers in the weak ductile crust and similar boundary conditions with respect to the Standard model. 

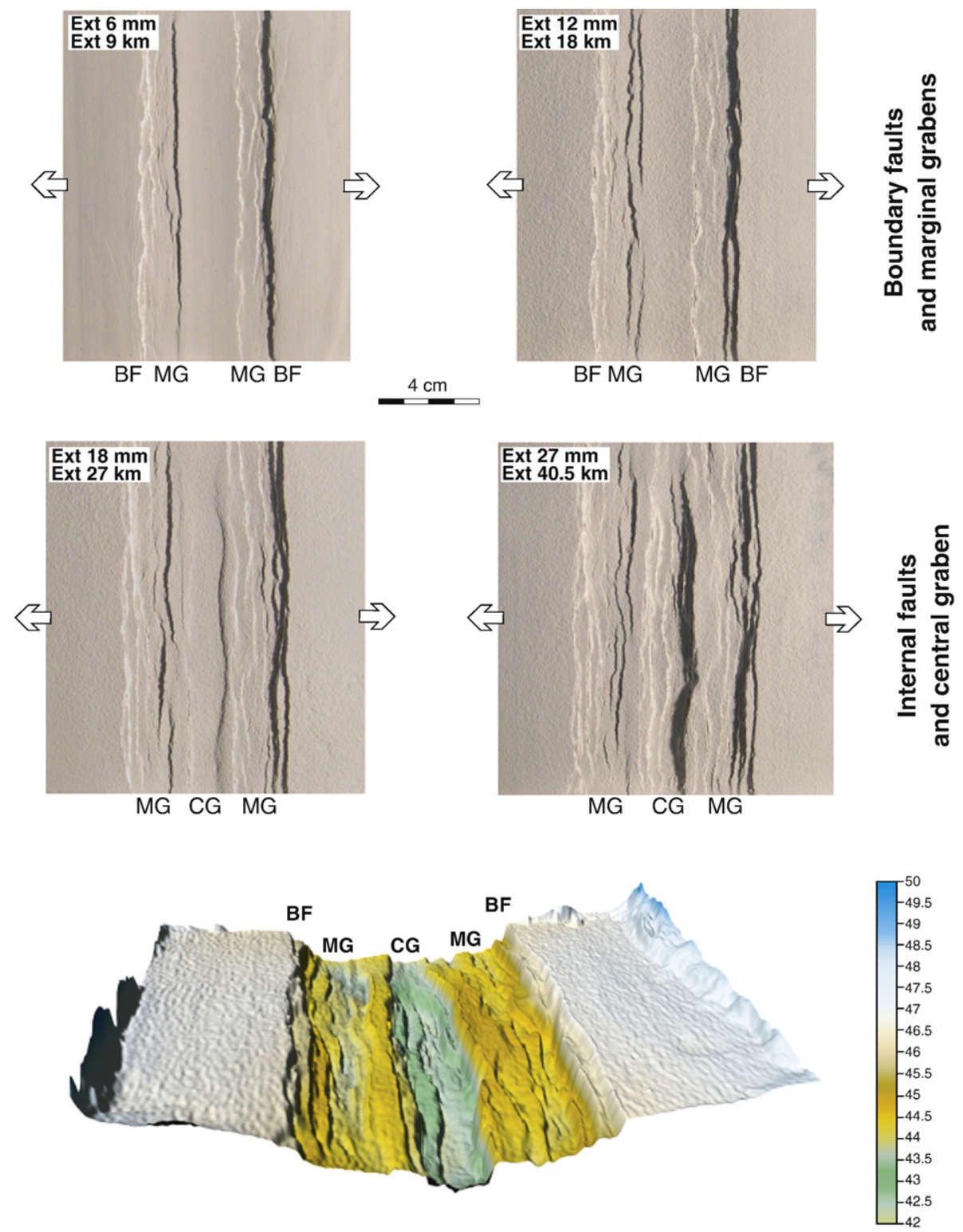

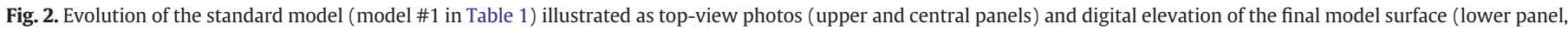

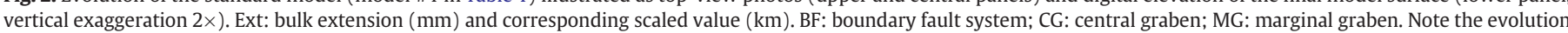

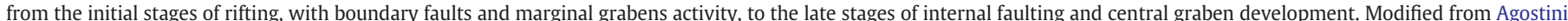
et al. (2009).

\section{Discussion}

4.1. Role of the pre-rift rheology of the continental lithosphere in the inward narrowing of tectonic activity

The pre-rift structure of the continental lithosphere is believed to exert a strong control on the process of continental rifting (e.g., Dunbar and Sawyer, 1989; Versfelt and Rosendahl, 1989; Morley, 1999; Tommasi and Vauchez, 2001; Ziegler and Cloetingh, 2004; Van Wijk, 2005; Corti, 2009; Keranen et al., 2009). For instance, the presence of lithospheric-scale inherited weaknesses and their reactivation may control rift kinematics (e.g., conditions of oblique rifting) and/or the along-axis rift architecture (e.g., rift kinks and transfer zones). The current experiments support this observation and document that the initial rheological layering may strongly control rift evolution, in particular the timing of the transition from rift boundary faults and basin subsidence that characterise the initial rift stages to the development of internal faults and graben-in-graben structures observed during later stages and incipient break-up (e.g., Ziegler and Cloetingh, 2004; Ebinger, 2005; Corti, 2009). Experiments suggest that the observed variability in the amount of previous extension, and therefore timing of the inward migration of deformation (and consequently duration of the rifting process) may result from the pre-rift rheology of the continental lithosphere, which is likely very complex and heterogeneous at the time of initial rifting, with important lateral variations in thickness and strength (e.g., Ziegler and Cloetingh, 2004). Thin upper and/or lower crust promotes a rapid abandonment of boundary faults and a transition to in-rift fault development after low amounts of extension. Conversely, thick upper and/or lower crust favour prolonged slip on boundary faults and later development of internal faulting. For the adopted boundary conditions, scaling of model results to nature suggests that duration of the boundary faults stage may vary from a minimum of $\sim 13.5 \mathrm{~km}$ bulk extension (i.e., $\sim 2.5 \mathrm{Ma}$ of extension for a velocity of $\sim 5 \mathrm{~mm} \mathrm{a}^{-1}$ ) to a maximum of $\sim 36 \mathrm{~km}$ bulk extension (i.e., $\sim 7 \mathrm{Ma}$ of extension for the same velocity), depending on the thickness of the brittle and ductile layers. 

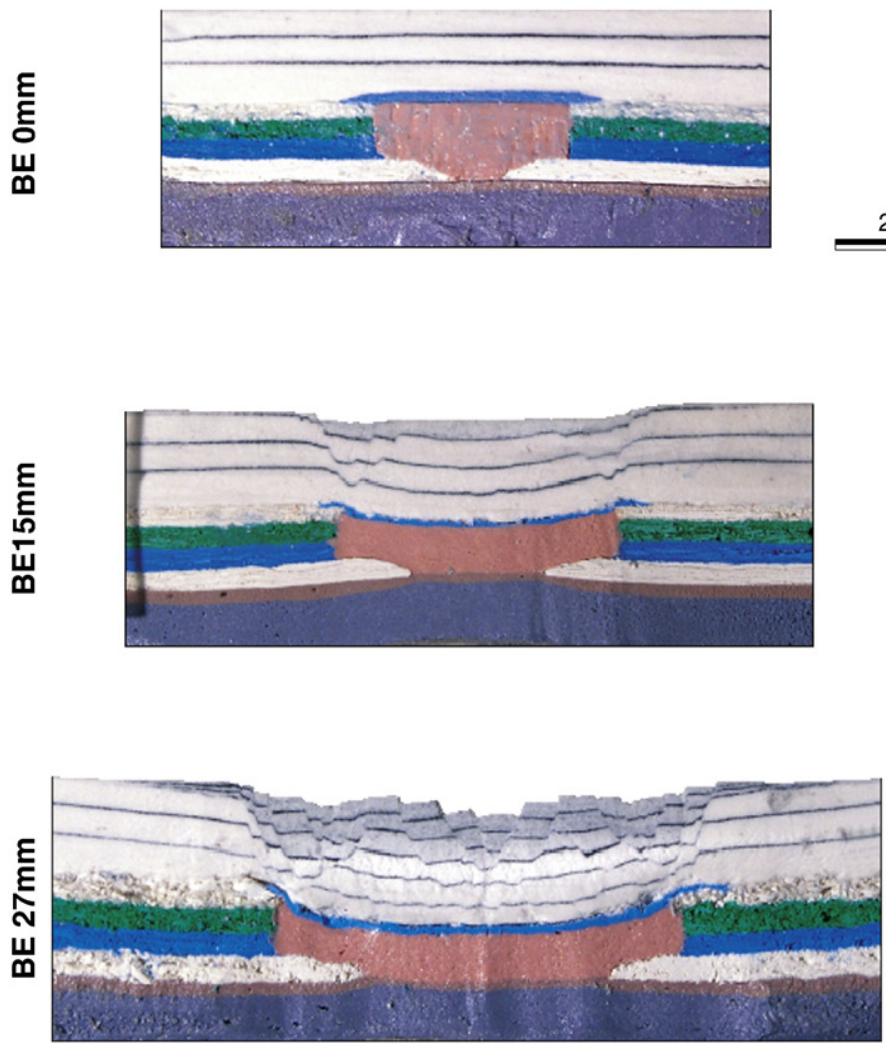

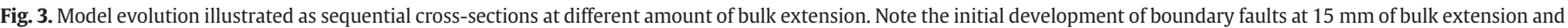
the well-developed system of internal faults at the end of the experiment ( $27 \mathrm{~mm}$ of bulk extension).
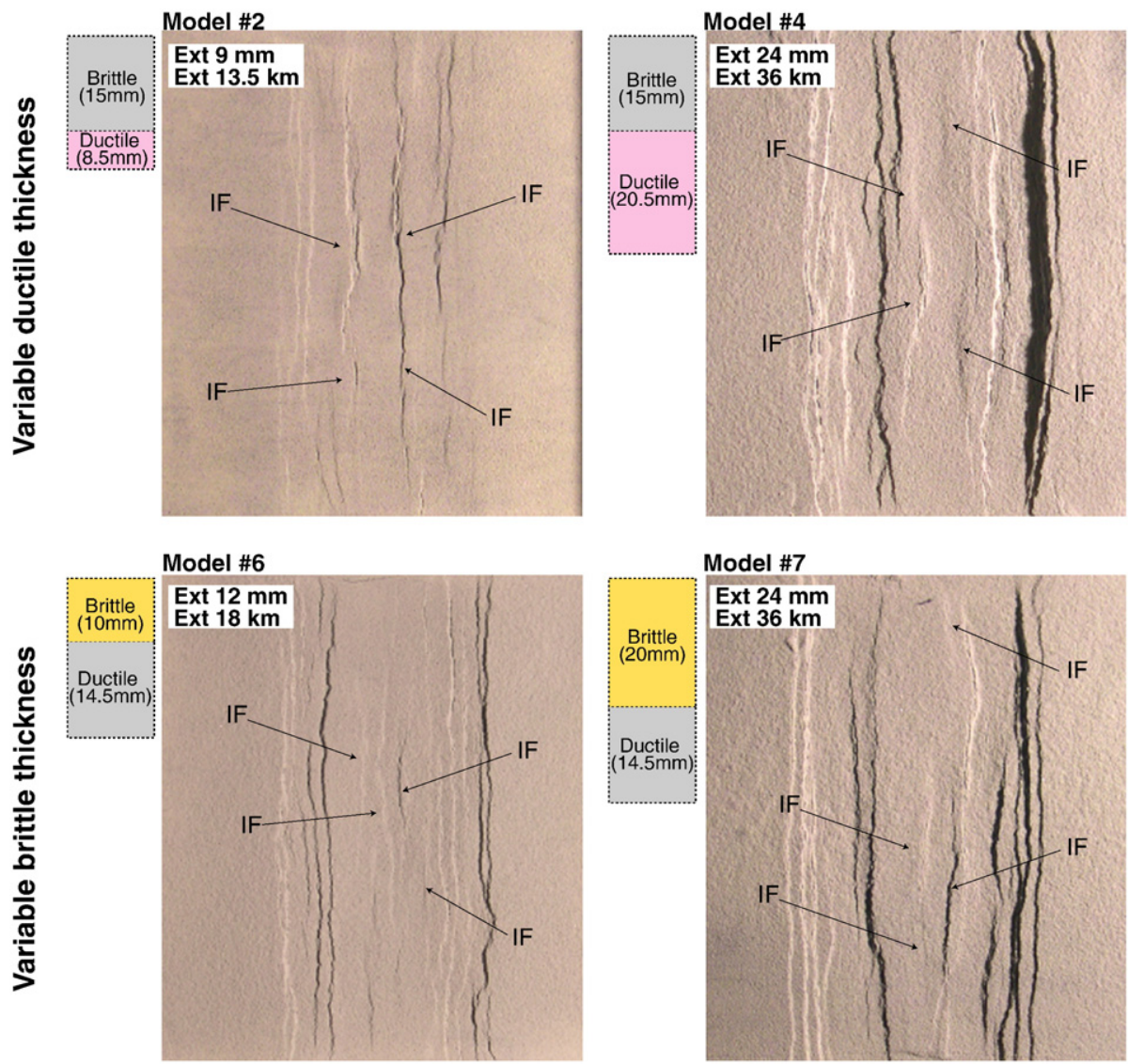

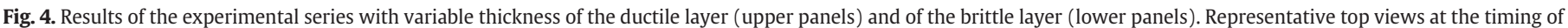

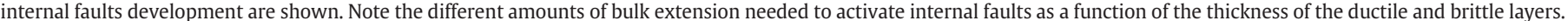


Variability in nature is much larger than that suggested by the current modelling, as duration of rifting may vary from less than $\sim 10 \mathrm{Ma}$ to $\sim 280 \mathrm{Ma}$ (see the compilation in Ziegler and Cloetingh, 2004). The difference between model and nature may be explained by different observations, such as: 1 ) the current models reproduce a $50 \mathrm{~km}$-thick lithosphere, such that thinning was much more effective in the models than in nature where lithospheric thickness may exceed $100-120 \mathrm{~km}$; including a larger lithospheric thickness would increase the difference between the lower and upper bound of the timing of migration; 2) moreover, nature is more complex than the current simple experiments and other processes (e.g., variation in strain rates and/or kinematics, changes in rheological properties of the lithospheric layers during extension, etc.) may contribute to increase the difference between the faster and slower migration patterns.

In addition to the effect of rheology, the current models suggest that while increased syn-rift sedimentation may favour prolonged slip on boundary faults and later development of internal faulting, a decreased rate of sedimentation permits rapid abandonment of border faults and a transition to in-rift fault development for low amount of extension. Thus, although future systematic analysis is needed to better explore the influence of erosion/sedimentation on extensional deformation, the first-order experimental results illustrate a control of sedimentation on rift evolution, as previously documented in natural
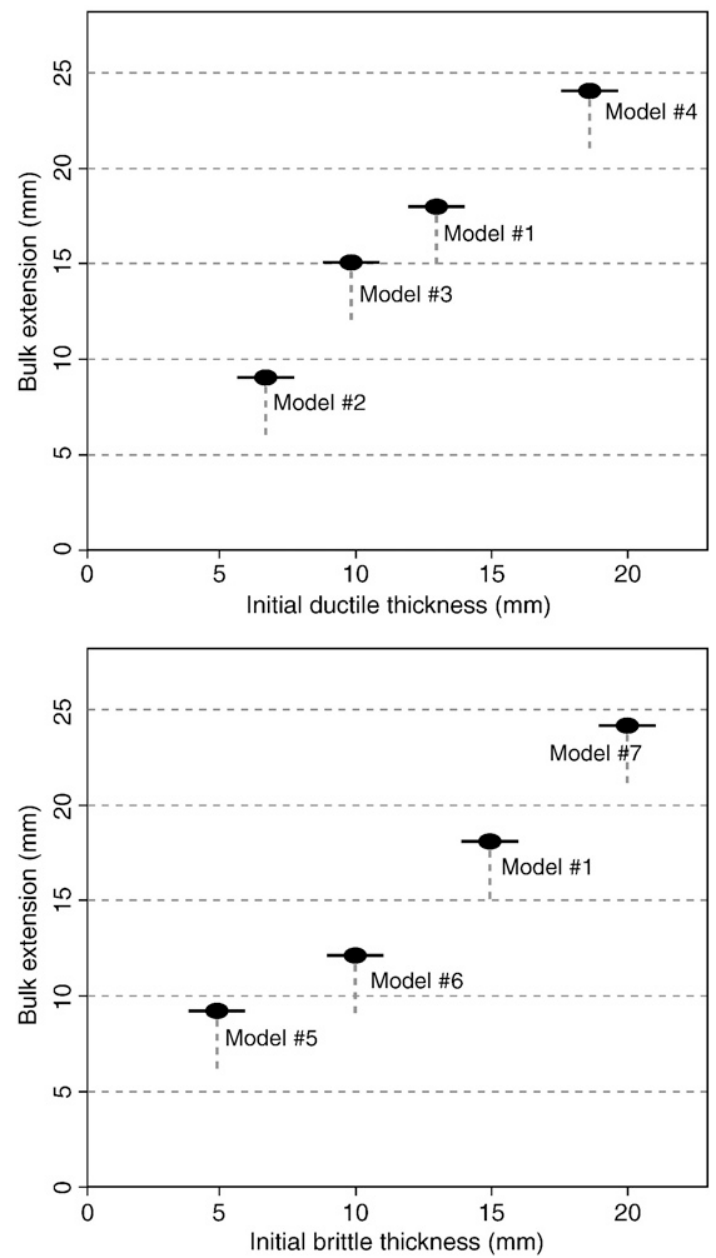

Fig. 5. Summary of experimental results illustrated as plots of the amount of bulk extension needed for deformation to migrate within the rift depression as a function of the thickness of the ductile layer (upper panel) and brittle layer (lower panel). The error bars in the horizontal direction indicate the variability in layer thickness introduced when building the model; the dashed bars in the vertical direction indicate the 3-mm deformation increment spanning the formation of the intra-rift faults observed at the end of the relevant centrifuge run (shown by the dot). settings (e.g., Lizarralde et al., 2007) and in numerical experiments (e.g., Bialas and Buck, 2009).

Although other external boundary conditions may influence the rift evolution, as for instance observed in experiments with variable rift obliquity (Agostini et al., 2009) and variable sideward displacement (i.e., episodic or steady rifting; Mulugeta and Ghebreab, 2001), the above results illustrate the fundamental control exerted by the pre-rift lithosphere structure and sediment supply on the evolution of continental rifting. The inward narrowing of tectonic activity during rifting appears to be related to the interplay between the resistance of the brittle layers and the stresses transmitted by the ductile layers (cf. discussion below).

\subsection{Dynamics of fault migration}

The two-phase rift evolution observed in the models is strongly controlled by the presence of the inherited weak zone and its thinning during extension. In particular, during the initial stages of extension, deformation is controlled by the strong rheological contrast at the margins of the weak zone where the velocity discontinuity between the strong and weak lithosphere produces differential thinning and

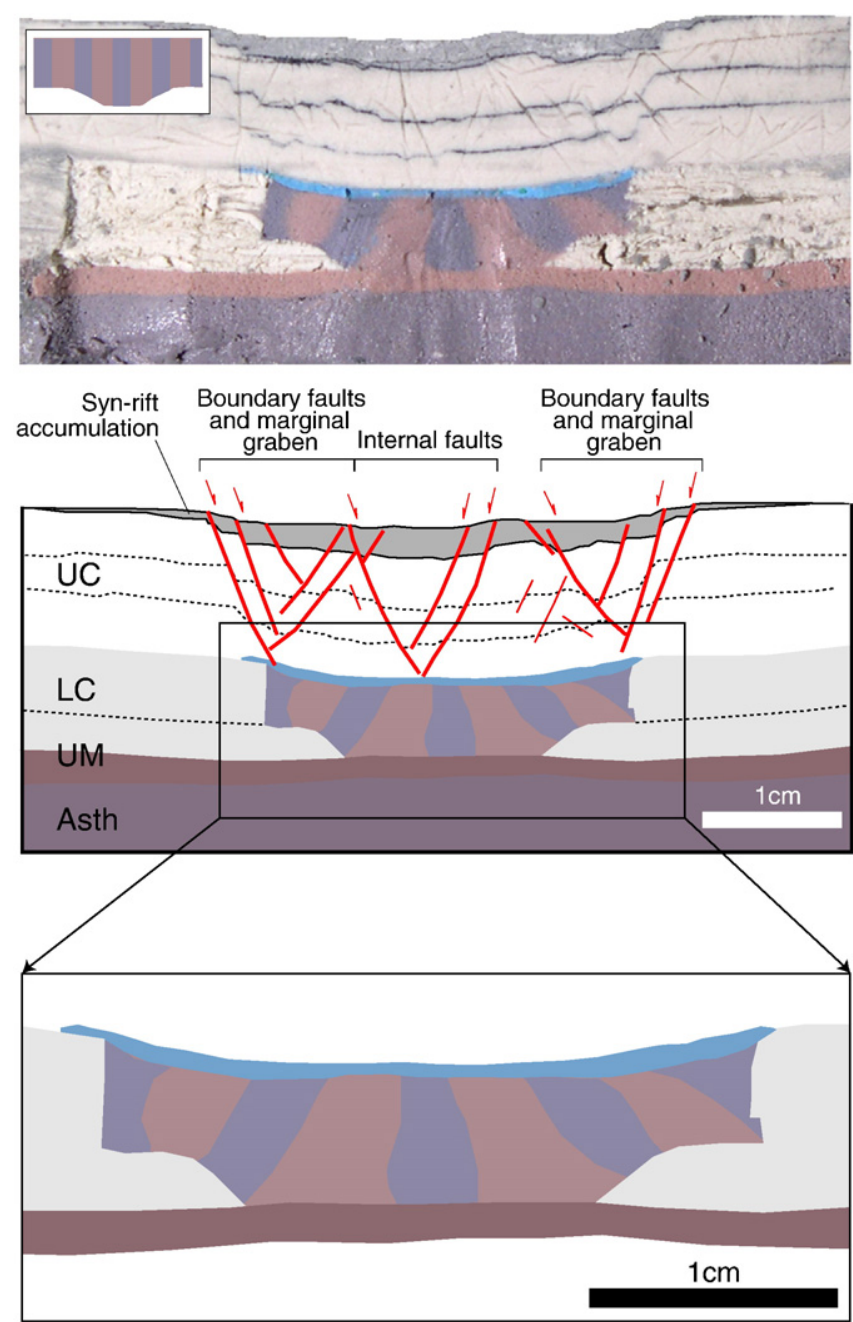

Fig. 6. Internal deformation of the ductile layer at the time of internal fault development, as observed in a test experiment performed with internal vertical markers in the weak ductile crust (see Table 1). Upper panel: photo of model crosssection; middle panel: line drawing of structures; lower panel: close up of the central part of the model. Note that purple and brown layers (initially vertical and $2 \mathrm{~mm}$ wide) were subjected both to lateral expansion and vertical rotation, denoting a combination of pure and simple shear deformation. 
hence induces high shear stresses at the base of the brittle crust. As a consequence, boundary faults develop above the rheological interface once the frictional resistance of the brittle layer is overcome. The brittle crust within the subsiding rift depression is undeformed during these initial stages of rifting.

Increasing extension leads to further thinning of the ductile layers above the uprising asthenosphere. Thinning occurs by a combination of pure and simple shear deformation of the weak ductile layer that accommodates the strong outward flow of the weak crust (Fig. 6; cf. also Brun and Beslier, 1996; Michon and Merle, 2003). Progressive thinning and strain localisation increase the ductile stresses at the base of the brittle layer, which act as driving forces for deformation and lead to fault migration when the total frictional resistance of the brittle crust is overcome (Fig. 7; see also Corti, 2008; Agostini et al., 2009). At this stage, faulting migrates inward with the development of new high-angle normal faults in the rift depression and activity on boundary faults decreases, a process that does not require influence of other parameters such as for instance a change in-rift kinematics and/ or localized voluminous magma injection into the extending lithosphere (e.g., Ebinger, 2005).

This analysis suggests that the process of fault migration in the models is controlled by the interplay between the ductile stresses at the base of the brittle layer (whose shear component appears to increase with decreasing ductile layer thickness; see Fig. 6) and the total resistance of the brittle layer (which scales directly with the brittle thickness and sediment accumulation). As a working hypothesis, we suggest that this interplay accounts for the dependence of the critical value of bulk extension needed for migration on the thickness of both brittle and ductile layers (Fig. 8). Increases in both the thickness of the ductile layer (which reduce basal shear stresses) and the thickness of the brittle layer and/or sediment supply (which increase the total frictional resistance) tend to delay the abandonment of boundary faults and in-rift fault development (Fig. 8).

The problem requires further study, since a quantitative analysis of the time-space evolution of internal deformation (e.g., variations in strain rates in ductile layers and strain localisation processes) is still
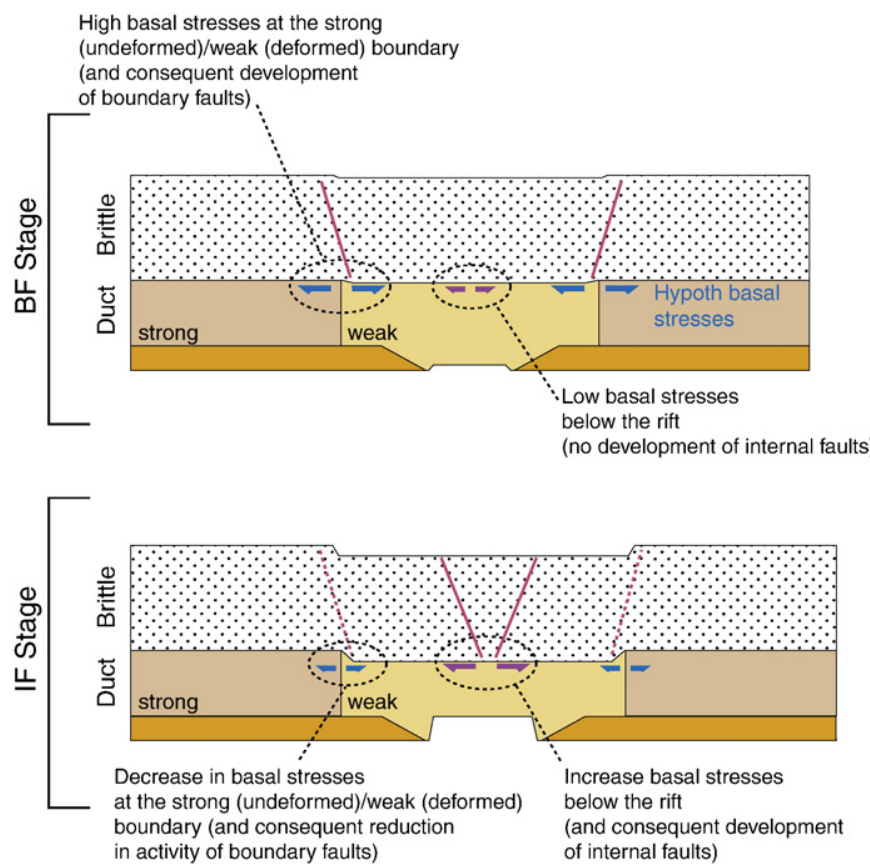

Fig. 7. Proposed evolution of extensional deformation based on model results. The hypothesized shear stresses acting at the base of the brittle crust in different portions of the model are shown. BF: boundary faults; IF: internal faults. See text for further details. Modified from Agostini et al. (2009). a

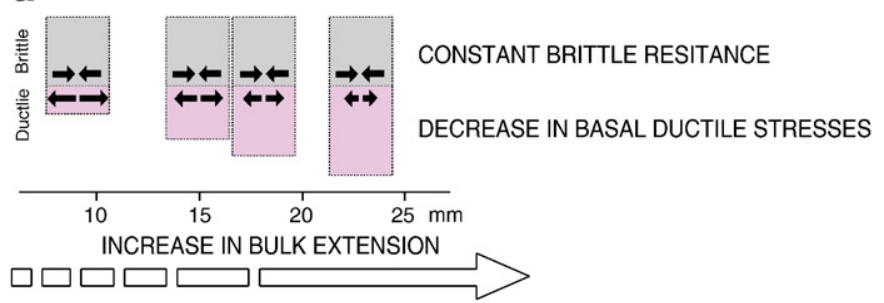

b

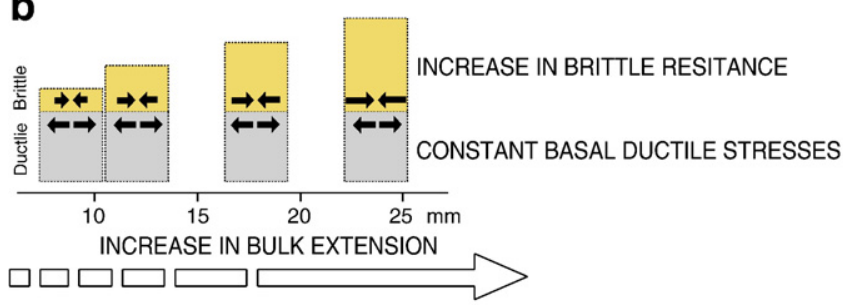

Fig. 8. Working hypothesis on the dynamics of fault migration in terms of the interplay between brittle resistance and basal ductile stresses during extension. Increases in the thickness of both ductile and brittle layers tend to delay the migration of faulting. See text for details.

lacking. However, the qualitative explanation proposed above agrees with the main results of the experiments and thus provides a reasonable hypothesis to account for the dynamics of the extensional process.

\section{Conclusions}

Continental narrow rifts undergo a typical two-phase evolution of deformation characterised by early activation of large boundary faults and basin subsidence (Boundary Faults stage) followed by later localization of tectonic activity in internal faults affecting the rift depression (Internal Faults stage). The analogue models presented in this paper reproduce this typical evolution and suggest that the amount of bulk extension needed for the transition between the two stages is a strong function of the pre-rift lithospheric structure (thickness of brittle and ductile crust) and syn-rift sediment accumulation. Early development of internal faults (i.e., rapid abandonment of boundary faults) occurs for thin upper and/or lower crust and absent or low syn-rift sedimentation; delayed migration of deformation (i.e., prolonged slip on boundary faults) is instead observed for thick upper and/or lower crust and high syn-rift sediment accumulation. A qualitative analysis of the process suggests that the interplay between brittle resistance and ductile stresses acting at the base of the upper crust may account for these experimental results.

\section{Acknowledgements}

We thank two anonymous reviewers for the critical comments which helped to improve this work. G.R.'s research is supported by a Discovery Grant from NSERC (Natural Sciences and Engineering Research Council of Canada).

\section{Appendix A. Supplementary data}

Supplementary data associated with this article can be found, in the online version, at doi:10.1016/j.tecto.2010.05.004.

\section{References}

Afonso, J.C., Ranalli, G., 2004. Crustal and mantle strengths in continental lithosphere: is the jelly sandwich model obsolete? Tectonophysics 394, 221-232.

Agostini, A., Corti, G., Zeoli, A., Mulugeta, G., 2009. Evolution, pattern and partitioning of deformation during oblique continental rifting: inferences from lithospheric-scale 
centrifuge models. Geochemistry, Geosphysics, Geosystems (GCubed) 10, Q11015. doi:10.1029/2009GC002676.

Bialas, R.W., Buck, W.R., 2009. How sediment promotes narrow rifting: application to the Gulf of California. Tectonics 28, TC4014. doi:10.1029/ 2008TC002394.

Bonini, M., Corti, G., Del Ventisette, C., Manetti, P., Mulugeta, G., Sokoutis, D., 2007. Modelling the lithospheric rheology control on the Cretaceous rifting in West Antarctica. Terra Nova 19, 360-366.

Brun, J.-P., 1999. Narrow rifts versus wide rifts: inferences for the mechanics of rifting from laboratory experiments. Philosophical Transactions of the Royal Society of London, Series A 357, 695-712. doi:10.1098/rsta.1999.0349.

Brun, J.-P., Beslier, M.O., 1996. Mantle exhumation at passive margins. Earth and Planetary Science Letters 142, 161-173.

Cloetingh, S., Van Wees, J.D., Van der Beek, P.A., Spadini, G., 1995. Extension in convergent regimes: constrains from thermo-mechanical modelling of Alpine/Mediterranean basins and intra-cratonic rifts. Marine and Petroleum Geology 12, 793-808.

Corti, G., 2005. Dynamics of periodic instabilities during stretching of the continental lithosphere: view from centrifuge models and comparison with natural examples. Tectonics 24, TC2008. doi:10.1029/2004TC001739.

Corti, G., 2008. Control of rift obliquity on the evolution and segmentation of the main Ethiopian rift. Nature Geoscience 1, 258-262.

Corti, G., 2009. Continental rift evolution: from rift initiation to incipient break-up in the Main Ethiopian Rift, East Africa. Earth Science Reviews 96, 1-53.

Corti, G., Manetti, P., 2006. Asymmetric rifts due to asymmetric Mohos: an experimental approach. Earth and Planetary Science Letters 245, 315-329. doi:10.1016/j.epsl.2006.02.004.

Corti, G., Bonini, M., Conticelli, S., Innocenti, F., Manetti, P., Sokoutis, D., 2003. Analogue modelling of continental extension: a review focused on the relations between the patterns of deformation and the presence of magma. Earth Science Reviews 63, 169-247.

Corti, G., Bonini, M., Sokoutis, D., Innocenti, F., Manetti, P., Cloetingh, S., Mulugeta, G., 2004. Continental rift architecture and patterns of magma migration: a dynamic analysis based on centrifuge models. Tectonics 23, TC2012. doi:10.1029/2003TC001561.

Corti, G., Bonini, M., Innocenti, F., Manetti, P., Piccardo, G.B., Ranalli, G., 2007a. Experimental models of extension of continental lithosphere weakened by percolation of asthenospheric melts. Journal of Geodynamics 43, 465-483.

Corti, G., van Wijk, J., Cloetingh, S., Morley, C.K., 2007b. Tectonic inheritance and continental rift architecture: numerical and analogue models of the East African Rift system. Tectonics 26, TC6006 http://dx.doi.org/10.1029/2006TC002086.
Dunbar, J.A., Sawyer, D.S., 1989. Continental rifting at pre-existing lithospheric weaknesses. Nature 242, 565-571.

Ebinger, C., 2005. Continental breakup: the East African perspective. Astronomy and Geophysics 46, 2.16-2.21.

Keranen, K., Klemperer, S.L., Julia, J., Lawrence, J.L., Nyblade, A., 2009. Low lower-crustal velocity across Ethiopia: is the Main Ethiopian Rift a narrow rift in a hot craton? Geochemistry Geophysics Geosystems 10, Q0AB01. doi:10.1029/2008GC002293.

Lizarralde, D., et al., 2007. Variable styles of rifting in the Gulf of California. Nature 448, 466-469.

Mart, Y., Dauteuil, O., 2000. Analogue experiments of propagation of oblique rifts Tectonophysics 316, 121-132.

McClay, K.R.., Dooley, T., Whitehouse, P., Mills, M., 2002. 4-D evolution of rift systems: Insights from scaled physical models. American Association of Petroleum Geologists Bulletin 86, 935-959.

Michon, L., Merle, O., 2003. Mode of lithospheric extension: conceptual models from analogue modeling. Tectonics 22, 1028. doi:10.1029/2002TC001435.

Morley, C.K., 1999. Influence of preexisting fabrics on rift structure. In: Morley, C.K. (Ed.), Geoscience of Rift Systems-Evolution of East Africa: American Association of Petroleum Geologists Studies in Geology, 44, pp. 151-160.

Mulugeta, G., Ghebreab, W., 2001. Modeling heterogeneous stretching during episodic or steady rifting of the continental lithosphere. Geology 29, 895-898.

Ramberg, H., 1981. Gravity, Deformation and the Earth's Crust. Academic Press, London. $452 \mathrm{pp}$.

Sokoutis, D., Corti, G., Bonini, M., Brun, J.-P., Cloetingh, S., Mauduit, T., Manetti, P., 2007 Modelling the extension of heterogeneous hot lithosphere. Tectonophysics 444, 63-79.

Tommasi, A., Vauchez, A., 2001. Continental rifting parallel to ancient collisional belts: an effect of the mechanical anisotropy of the lithospheric mantle. Earth and Planetary Science Letters 185, 199-210.

van Wijk, J.W., 2005. Role of weak zone orientation in continental lithosphere extension. Geophysical Research Letters 32. doi:10.1029/2004GL022192.

Versfelt, J., Rosendahl, B.R., 1989. Relationships between pre-rift structure and rift architecture in Lakes Tanganyika and Malawi: East Africa. Nature 337, 354-357.

Ziegler, P.A., Cloetingh, S.A.P.L., 2004. Dynamic processes controlling evolution of rifted basins. Earth Science Reviews 64, 1-50. 